\title{
Gold-Catalyzed Carboamination of Allenes by Tertiary Amines Proceeding with Benzylic Group Migration
}

\author{
Pierre Milcendeau, ${ }^{a}$ Vincent Gandon, ${ }^{\mathrm{b}, \mathrm{c}}{ }^{*}$ Xavier Guinchard ${ }^{\mathrm{a}}$ *
}

a Université Paris-Saclay, CNRS, Institut de Chimie des Substances Naturelles, UPR 2301, 91198, Gif-sur-Yvette, France. xavier.guinchard@cnrs.fr ; (+33)169824582

b Institut de Chimie Moléculaire et des Matériaux d’Orsay, CNRS UMR 8182, Université Paris-Saclay, Bâtiment 420, 91405 Orsay cedex, France. vincent.gandon@universite-paris-saclay.fr

c Laboratoire de Chimie Moléculaire (LCM), CNRS UMR 9168, Ecole Polytechnique, Institut Polytechnique de Paris, route de Saclay, 91128 Palaiseau cedex, France

Tertiary amines bearing a benzyl-type group $\left(\mathrm{CH}_{2} \mathrm{Ar}\right)$ undergo $\mathrm{Au}(\mathrm{I})$-catalyzed intramolecular addition to allenes. A formal 1,3-transfer of the $\mathrm{CH}_{2} \mathrm{Ar}$ group takes place during the cyclization. As demonstrated by both experimental and DFT studies, these unprecedented intramolecular carboaminations involve two consecutive [3,3] rearrangements via a dearomatized intermediate. Because of the poor stability of the enamine products, protocols were developed to convert them in situ to more stable polycyclic chiral compounds.

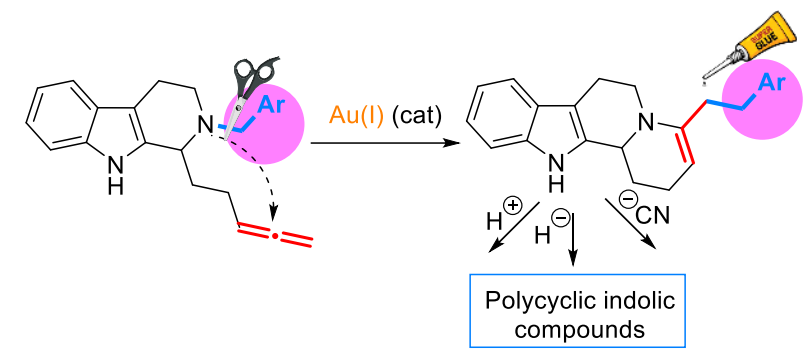

After almost two decades of intense research, homogeneous gold catalysis has established itself as an inescapable field in organic synthesis. ${ }^{[1],[2]}$ The $\pi$-acidic properties $A u(I)$ complexes enable a vast range of catalytic reactions, leading to a huge structural diversity. Among the popular reactivity of these complexes, hydrofunctionalizations of unsaturated substrates hold a salient position. The diversity of nucleophiles combined with various unsaturated electrophilic partners lead to an efficient access to a number of important heterocycles. ${ }^{[3]}$ In most cases, the reactions evolve through a general similar pathway combining 1) activation of the unsaturation, 2) addition of the nucleophile and 3 ) protodeauration reaction. This strategy was very efficiently applied to hydrofunctionalization ${ }^{[4]}$ of alkynes, ${ }^{[5]}$ allenes ${ }^{[6]}$ or alkenes (Scheme 1 , type A).$^{[7]}$ In some reactions though (mainly from alkenes), it is possible to oxidize the intermediate gold species and promote an additional functionalization by a nucleophile resulting most of the time into a formal double heterofunctionalization (Scheme 1, type B). ${ }^{[1 h, 8],[9]}$ However, reactions performed with functionalized nucleophiles (no X-H bond), for which the protodeauration step cannot take place, may lead to both cyclization and a transfer of the functional group via intriguing mechanisms (Scheme 1, type C). In these reactions, no external oxidant is needed since no redox cycle operates. A number of chemical functions have been shown to efficiently transfer during the cyclizations of $\mathrm{O}$-, $\mathrm{N}$ - or $\mathrm{S}$ - centered nucleophiles to mostly alkynes electrophiles, such as alkyl, ${ }^{[10]}$ silyl, ${ }^{[11]}$ arylidene, ${ }^{[12]}$ propargyl ${ }^{[13]}$ or allyl groups. ${ }^{[10 a, 14]}$ All these reactions raise questions 
regarding the associative of dissociative nature of the mechanism, which appears to be strongly depends on the heteroatom and the migratory group.

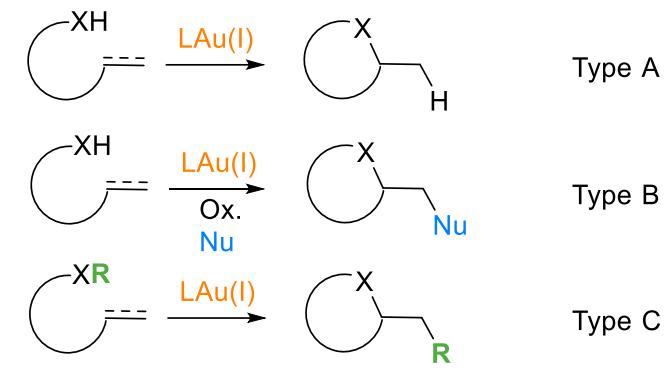

Scheme 1. General heterocyclization processes with $\mathrm{Au}(\mathrm{I})$ catalysts

Over the last years, we have developed a number of $A u(I)$-catalyzed strategies to the functionnalization of indoles. ${ }^{[15],[16]}$ Recently, we pioneered a new type of intramolecular cyclizations from $\mathrm{N}$ allyltetrahydro- $\beta$-carbolines that undergo gold-catalyzed carboamination of their allene moiety, resulting in cyclization products with the concomitant 1,3-migration of the allyl group (Scheme 2, eq. 1). ${ }^{[17]}$ Seeking to question the possibility to do related cyclizations with more challenging migrating groups, we hypothesized that benzylic groups should lead to structurally resembling compounds, with the migration of the whole $\mathrm{CH}_{2} \mathrm{Ar}$ group. To our knowledge however, there is a single example of a cyclization occuring with a transfer of a $p$-MeOBn upon gold catalysis, reported solely in a review. ${ }^{[18]}$ In addition, precedents from Hashmi evidenced the difficulty to transfer benzyl groups in related reactions, ${ }^{[14 c]}$ likely because of the energetically demanding dearomatization in intermediate $\boldsymbol{i}$ (Eq. 2). ${ }^{[19]}$ It is however not to exclude that some aryls groups may be able to participate to such reactions, and we anticipated that tetrahydro- $\beta$-carbolines 1 could lead to indolo[2,3-a]quinolizidines $\mathbf{2}$ via the ammonium salt $\boldsymbol{i i}$ and the dearomatized intermediate $\mathbf{i i i}$, that would further undergo an additional $[3,3]$ sigmatropic rearrangement (Scheme 2, eq. 3).
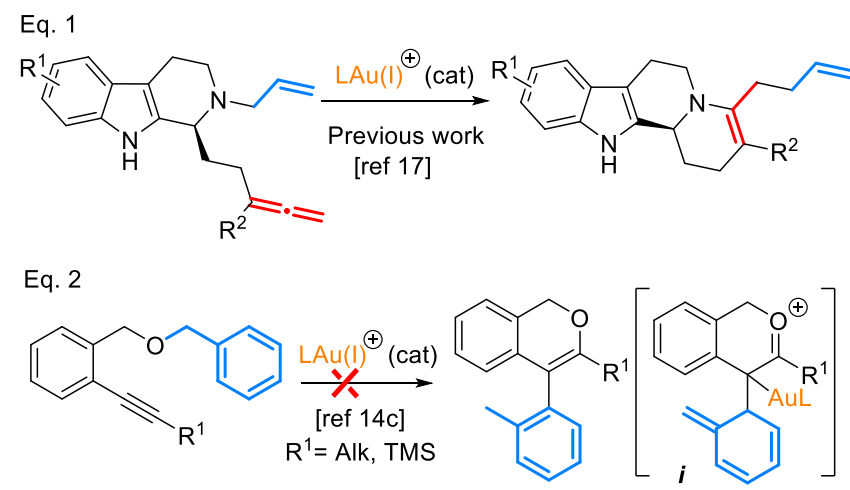

Eq. 3

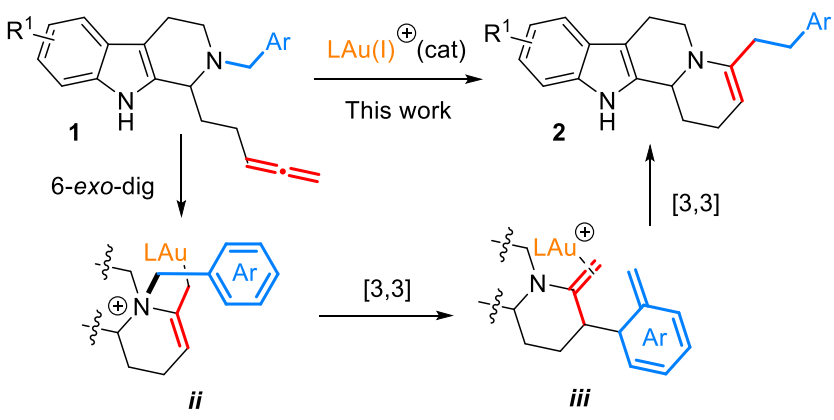

Scheme 2. Au(I)-catalyzed carboamination of allenes 
In this paper, we show that a range of $\mathrm{CH}_{2} \mathrm{Ar}$ groups can be efficiently transferred and lead to valuable molecules. The whole process was also applied to different scaffolds. A DFT study assessed the mechanistic hypothesis.

We first prepared in good yields a series of tetrahydro- $\beta$-carbolines 1 by using the Pictet-Spengler reaction ${ }^{[20]}$ between a series of tryptamines protected by a range of benzylic groups and hexa-4,5-dienal.
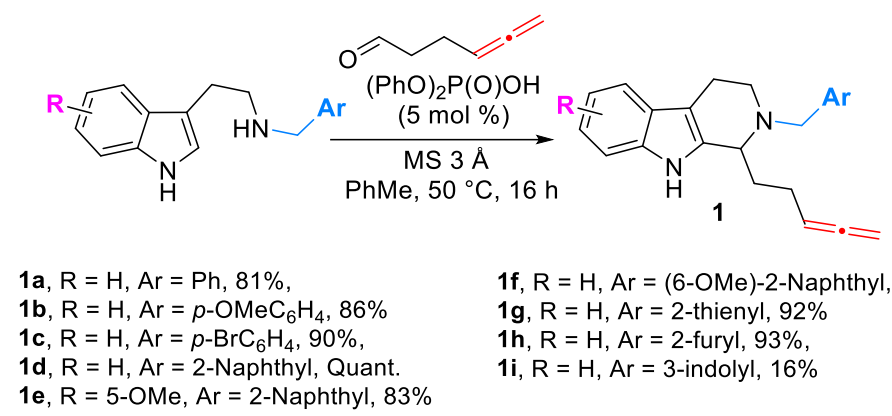

1f, $\mathrm{R}=\mathrm{H}, \mathrm{Ar}=(6-\mathrm{OMe})-2-\mathrm{Naphthyl}, 96 \%$

1g, $\mathrm{R}=\mathrm{H}, \mathrm{Ar}=2$-thienyl, $92 \%$

$1 \mathrm{~h}, \mathrm{R}=\mathrm{H}, \mathrm{Ar}=2$-furyl, $93 \%$,

1i, $\mathrm{R}=\mathrm{H}, \mathrm{Ar}=3$-indolyl, $16 \%$

Scheme 3. Synthesis of tetrahydro- $\beta$-carbolines 1

A suitable catalytic system was sought using tetrahydro- $\beta$-carbolines 1 as substrates (Table 1 ). We first engaged $1 \mathbf{a}$ in the reaction with the JohnPhosAuSbF 6 . MeCN catalyst ${ }^{[21]}$ 3a in toluene (Table 1, entry 1 ), but no conversion was observed. The effect of an electron donating group and a halogen were checked using compounds $\mathbf{1} \mathbf{b}$ and $\mathbf{1 c}$ but, again, no reaction took place (Entries $2-3$ ). Those results confirmed that benzylic groups embedding a phenyl ring do not undergo the dearomatization step included in the mechanistic hypothesis. On the other hand, when the naphthylmethyl-protected tetrahydro- $\beta$-carboline $\mathbf{1} \mathbf{d}$ was used, a high NMR conversion of $\mathbf{1} \mathbf{d}$ in $\mathbf{2} \mathbf{d}$ was monitored, in particular when the solvent was switched to DCE (entries 4-7). Both the Gagosz catalyst ${ }^{[22]}$ and the $\operatorname{IPrAuBF}_{4}$ complex showed lower activity (entries 8-9). Further studies revealed that the reaction necessitates shorter reaction time ( $4 \mathrm{~h}$, entry 10$)$ but that a lower catalyst loading results in a significant decrease in the catalytic activity despite prolonged reaction times (entry 11).

Table 1. Optimization of the catalytic system using 1a-d

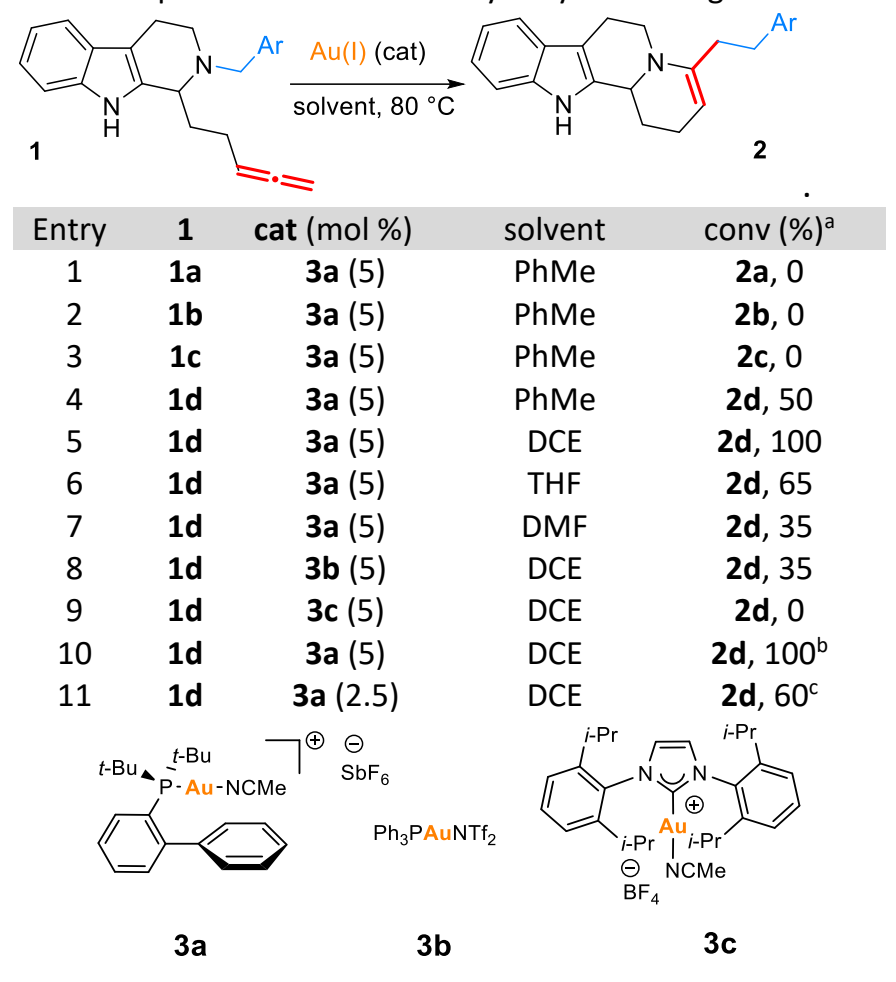


a) Measured by ${ }^{1} \mathrm{H}$ NMR. Reactions were performed for $16 \mathrm{~h}$. b) Reaction performed over $4 \mathrm{~h}$. c) Reaction performed over $24 \mathrm{~h}$.

As we observed in our previous studies, ${ }^{[17]}$ the enamine nature of product $\mathbf{2} \mathbf{d}$ complicates its purification and isolation because of its high reactivity. For this reason, we established two different protocols to directly convert compounds $\mathbf{2} \mathbf{d}$ into a stable product (Scheme 4 ). In a first approach, we directly reduced the enamine resulting from the carboamination to the corresponding amine by addition of $\mathrm{NaBH}_{4}$ and $\mathrm{MeOH}$ after completion of the $\mathrm{Au}(\mathrm{I})$-catalyzed reaction. This resulted in the formation of compound $\mathbf{4 d}$ as a single diastereoisomer in $\mathbf{7 3 \%}$ yield (See the Supporting Information for optimization of the reduction). NOESY studies revealed that compound $\mathbf{4 d}$ is cis-configured. In a second valorization strategy of the unstable enamine product $\mathbf{3 d}$, we added aqueous $\mathrm{HCl}$ to promote its hydrolysis and protected in situ the resulting amine with a Boc group to lead to the stable ketone $\mathbf{5 d}$ in $79 \%$ yield. ${ }^{[23]}$ At the end, the product obtained results from a formal carbohydration of the allene, though the mechanism evolves through a carboamination. This constitutes an interesting approach, since direct carbohydration of allenes systems is, to our knowledge, not reported in the literature, in sharp contrast with hydration ${ }^{[24]}$ and carboalkoxylation ${ }^{[25]}$ with gold, or other transition metals. ${ }^{[26],[27]}$

We next engaged other tetrahydro- $\beta$-carbolines 1 in the gold-catalyzed carboamination and applied for each substrate both the reductive and the hydrolytic protocols. The reaction tolerated the presence of a methoxy group at position 5 of the indole ring, resulting in the isolation of both $4 e$ and $5 e$, in $60 \%$ and $46 \%$ yield, respectively. We also confirmed that the 7-methoxynaphthylmethyl group allows the carboamination process to $\mathbf{4 f}$ in $69 \%$ yield. When the acidic workup was applied, product $\mathbf{5 f}$ was obtained in $65 \%$ yield. Finally, the 2 -thienylmethyl moiety also participated in the reaction, leading to $\mathbf{4 g}$ and $\mathbf{5 g}$ in good yields.

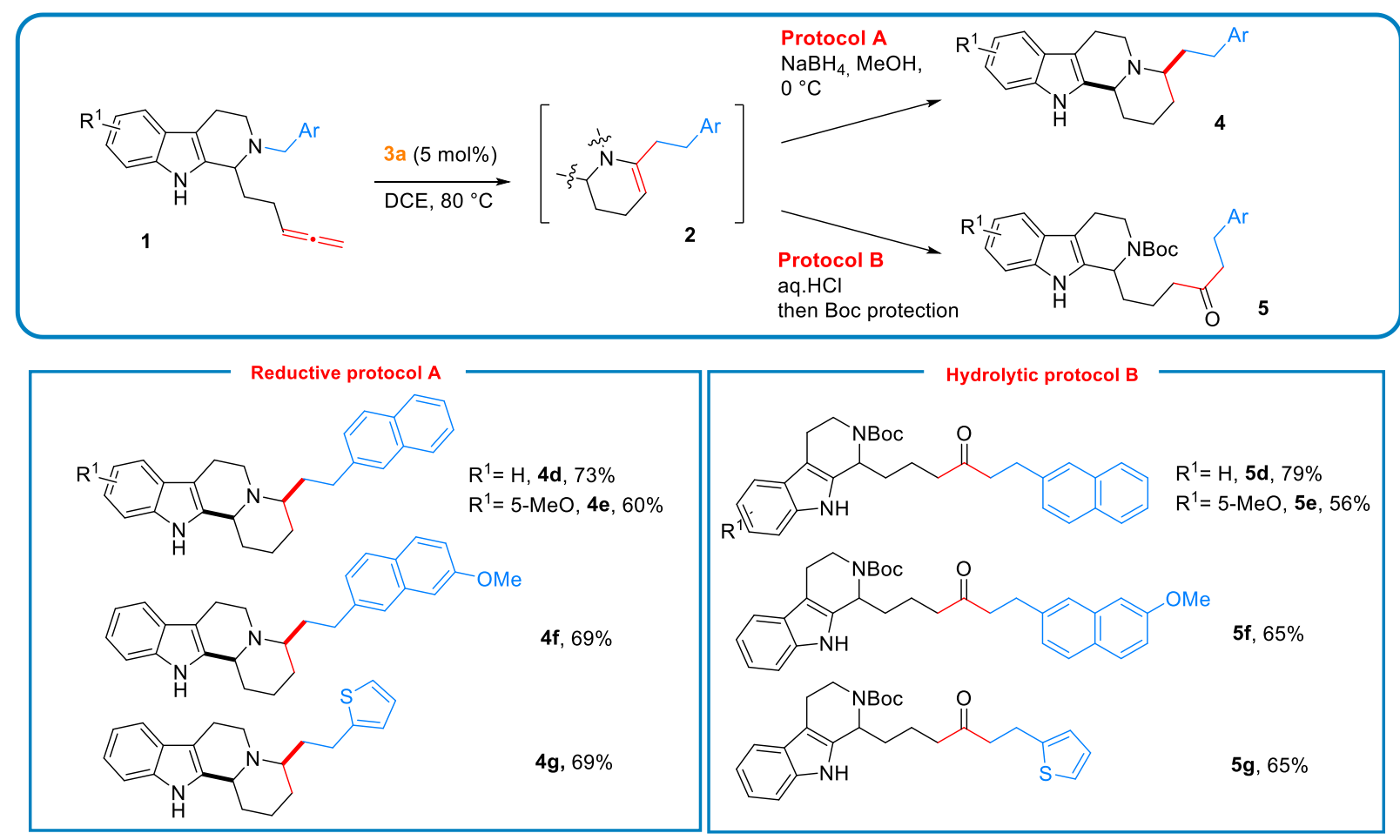

Scheme 4. Scope of the Reaction 
Interestingly, the analogous compound $\mathbf{1 h}$ bearing a furylmethyl group undergoes the cyclization but delivered very selectively compound $\mathbf{6}$ instead of the expected compound $\mathbf{2 h}$ (Scheme 5, eq. 1), likely stemming from a direct rearomatization (see intermediate iii, Scheme 2) and not a [3,3] rearrangement. This compound is however poorly stable on silica gel but could be fully characterized as a mixture with the catalyst (See the Supporting Information). When the hydrolysis workup B was applied to the crude mixture, compound 7 was obtained in $42 \%$ yield after Boc protection (eq. 2 ).

Interestingly, the tetrahydro- $\beta$-carboline $\mathbf{1 i}$ also evolved through an original pathway, leading to compound $\mathbf{8}$ as the main identifiable product of the reaction, that we previously obtained using palladium catalysis ${ }^{[28]}$ (eq. 3). Most likely, this products arises from the 5-exo-trig cyclization of the amine to the allene ${ }^{[29]}$ leading to intermediate $\boldsymbol{i}$, followed by the cleavage of the nitrogen-indolylmethyl bond, forming an azafulvenium ion ii and protodeauration of intermediate iii by mean of the azafulvene ion.

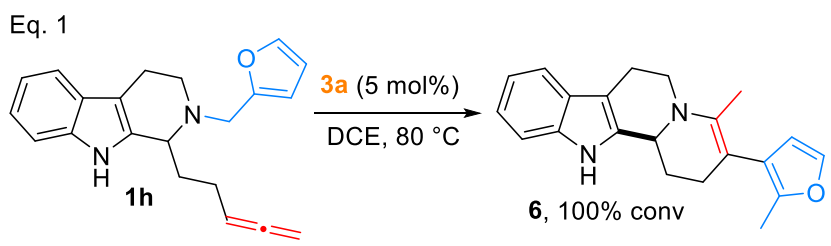

Eq. 2

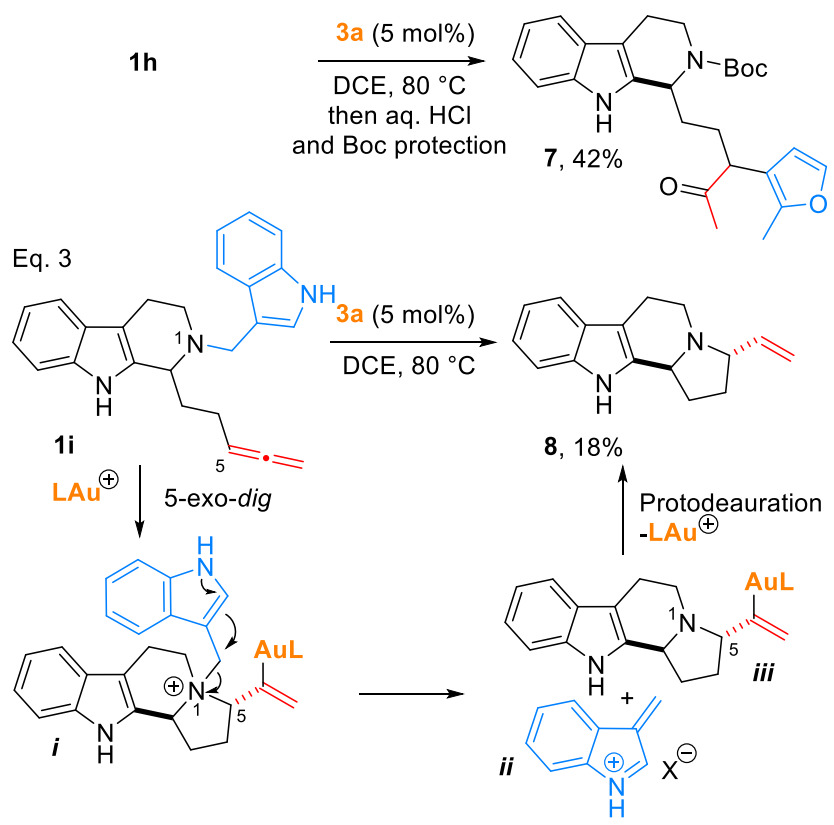

Scheme 5. Au(I)-catalyzed cyclizations with furyl and indolyl substituents

During the optimization process, an interesting observation arose from cyclization experiments performed from $\mathbf{1 d}$ in nitromethane with catalyst 3a (Scheme 6, eq. 1). This reaction furnished the nitro compound $9 \mathbf{d}$ with full conversion as a couple of diastereomers ( $\mathrm{dr} 75 / 25)$. This compound likely results from the nucleophilic addition of nitromethane to the intermediate enamine $\mathbf{2 d}$. It is however not stable on silica gel and undergoes elimination leading to the final product $\mathbf{2 d}$. Because of its intrinsic instability, compound $9 \mathbf{d}$ could be characterized only as the crude product without removal of the catalyst (see the Supporting Information) and its structure was also confirmed by HRMS. Interestingly, when the reaction was performed in deuterated nitromethane, the ${ }^{1} \mathrm{H}$ NMR spectra of the product fitted that of $9 \mathrm{~d}$, with however the disappearance of the two protons adjacent to the nitro group and of two additional $\mathrm{CH}_{2}$ (eq. 2). 
In order to confirm that $\mathbf{9 d}$ is indeed formed from enamine $\mathbf{2} \mathbf{d}$ and if the $A u(I)$ catalyst plays a role in its formation, a batch of enamine $\mathbf{2} \mathbf{d}$ (as pure as possible despite its instability, see the Supporting Information) was then stirred at $80^{\circ} \mathrm{C}$ in deuterated nitromethane in the presence or absence of the gold catalyst (eq. 3 ). In the absence of the catalyst, despite the full conversion of $\mathbf{2} \mathbf{d}$, the reaction showed only traces of $9 \mathbf{d}$ and led mainly to degradation. On the contrary, in the presence of catalyst 3a, the formation of $\mathbf{9 d}$ was confirmed, even if the reaction was not complete (ca $55 \%$ conv.), confirming the role of the $\mathrm{Au}(\mathrm{I})$ catalyst in this step. Nitro-Mannich reactions have already been catalyzed by Lewis acids, ${ }^{\left[{ }^{30]}\right.}$ but to our knowledge, this behavior is not common for enamines in $\mathrm{Au}(\mathrm{I})$ catalysis and has never been documented. Our hypothesis is that enamine $\mathbf{2} \mathbf{d}$ coordinates the $\mathrm{Au}(\mathrm{I})$ complex to generate iminium (i), that is trapped by the nitromethane in the course of the Aza-Henry reaction leading to (ii). Finally, protodeauration generates the final product $9 \mathrm{~d}$ (eq. 4). The cyclization performed in deuterated nitromethane corroborates well this hypothesis.
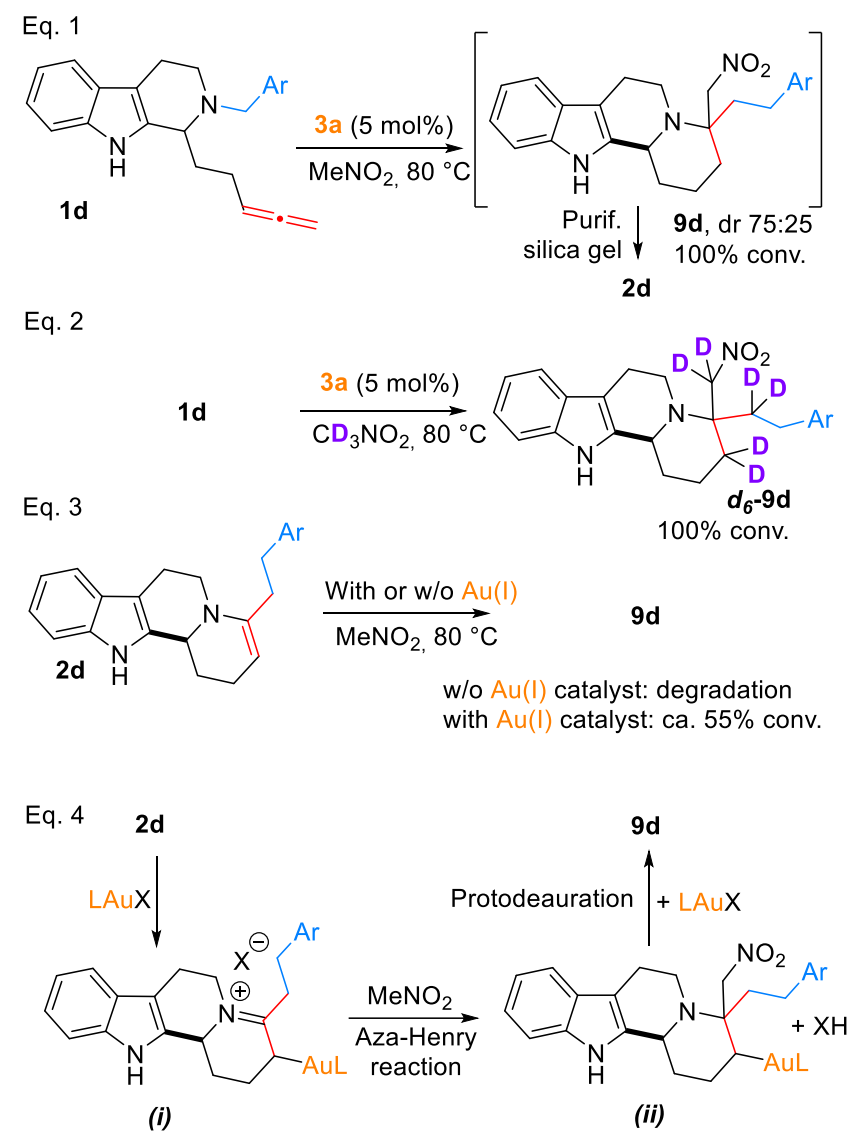

Scheme 6. Cyclizations using $\mathrm{MeNO}_{2}$ as solvent

Since these results in nitromethane showed that a $C$-centered nucleophile could act as a trapping agent, we next attempted to trap the enamine product $\mathbf{2} \mathbf{d}$ with trimethylsilylcyanide. The addition of TMSCN after the Au(I)-catalyzed cyclization of $\mathbf{1 d}$ gratifyingly led to the formation of the cyanide $\mathbf{1 0 d}$, isolated with $53 \%$ yield as a single diastereomer (Scheme 7). NOESY NMR analysis showed that the cyanide was delivered on the same side of the enamine than when $\mathrm{NaBH}_{4}$ was used. In contrast with compound $\mathbf{9 d}, \mathbf{1 0 d}$ showed great stability both on silica gel and upon storage.

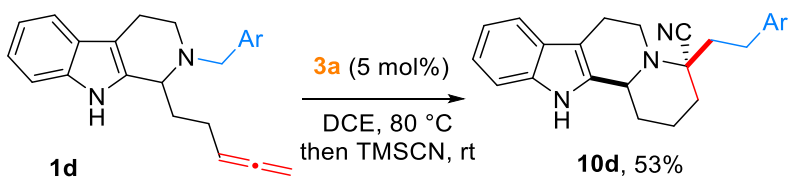

Scheme 7. Extension of the reactivity to the cyanation of intermediate product $\mathbf{2 d}$. Ar= 2-naphthyl 
In order to secure the initial mechanistic hypothesis, we first verified experimentally that the reaction operates solely via an intramolecular mechanism by using cross experiments (see the Supporting Information).

The model cyclization of tetrahydro- $\beta$-carbolines $1 \mathbf{a}(\mathrm{Ar}=\mathrm{Ph})$ and $\mathbf{1 d}(\mathrm{Ar}=2$-naphthyl) were studied by DFT computations with the JohnPhos ligand on the gold atom and compared with those reported earlier with a vinyl group ${ }^{[17]}$ (see the Supporting Information for details). All energies are Gibbs free energies in $\mathrm{kcal} / \mathrm{mol}$ at $353 \mathrm{~K}$ including a solvent correction for dichloromethane. The computed mechanistic options are shown in Figure 1. Starting from the allene gold(I) complex A, a 6-exo-dig cyclization leads to the allylgold species B. A suprafacial [3,3]-sigmatropic shift of the $\mathrm{CH}_{2} \mathrm{R}$ group provides the exo-enamine gold complex $\mathbf{C}$. A second [3,3]-sigmatropic shift transforms the latter into

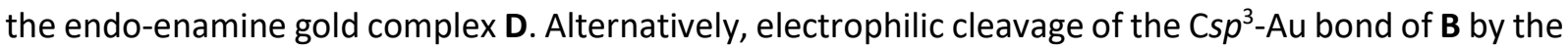
$\mathrm{CH}_{2} \mathrm{R}$ group leads to $\mathbf{D}$ directly, but this could be only modeled with $\mathrm{R}=$ vinyl. From $\mathbf{C}$, one can imagine a proton elimination that would lead to the allylgold species $\mathbf{E}$. Protodemetallation finally gives $\mathbf{F}$, which is actually the isolated product when $R=$ vinyl. On the other hand, a simple dissociation of the active species $\mathrm{LAu}^{+}$from $\mathbf{D}$ delivers $\mathbf{H}$ (=compounds $\mathbf{2}$ ), which is experimentally obtained when $\mathrm{R}=\mathbf{2}$-naphthyl $\left(\mathbf{H}_{\mathrm{d}}=\mathbf{2 d}\right)$. Another scenario to get $\mathbf{2}$ would be the dissociation of $\mathrm{LAu}^{+}$from $\mathbf{C}$ to give $\mathbf{G}$, followed by a $[3,3]$-sigmatropic shift (Cope rearrangement).

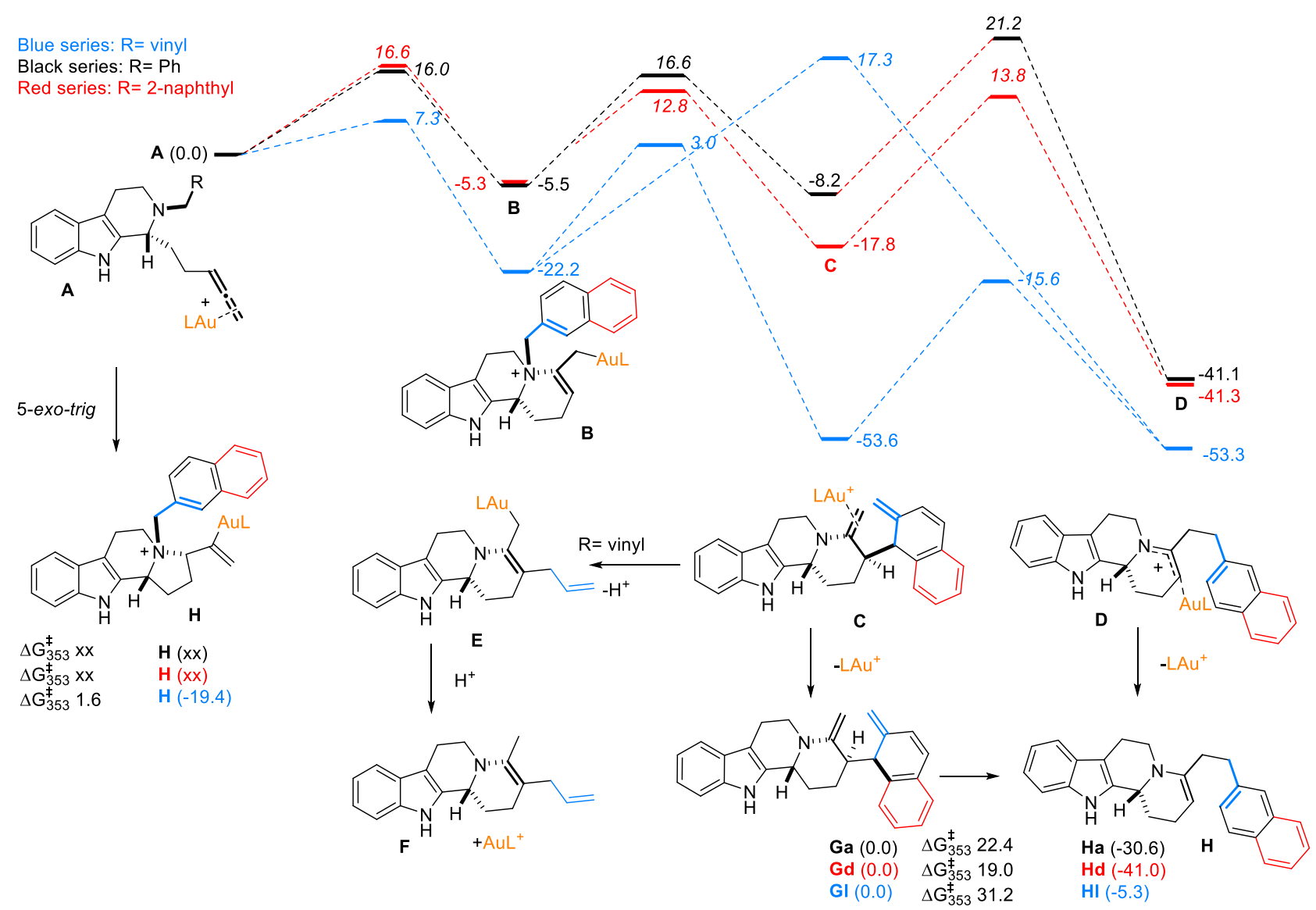

Figure 1. Free Energy Profile $\left(\Delta \mathrm{G}_{353}, \mathrm{kcal} / \mathrm{mol}\right)$ Relatively to Complex $A$ (free energies of the transition states are in italics)

The formation of $\mathbf{B}$ through $\mathbf{T S} \mathbf{S}_{\mathbf{A B}}$, appears kinetically and thermodynamically much more favorable with $R=$ vinyl. The second step requires $25.2 \mathrm{kcal} / \mathrm{mol}$ of free energy of activation to reach $\mathbf{T S}_{\mathrm{BC}}$ with $\mathrm{R}$ $=$ vinyl, $22.1 \mathrm{kcal} / \mathrm{mol}$ with $\mathrm{R}=\mathrm{Ph}$ and $18.1 \mathrm{kcal} / \mathrm{mol}$ with $\mathrm{R}=2$-naphthyl. ${ }^{[31]}$ There is a strong difference 
in the exergonicity of this step, which is very strong with $R=$ vinyl $(-31.4 \mathrm{kcal} / \mathrm{mol})$, weak with $R=P h(-$ $2.7 \mathrm{kcal} / \mathrm{mol}$ ) and average with $\mathrm{R}=2$-naphthyl $(-12.5)$. This can be explained by the loss of aromaticity in the latter two cases compared to the former. This loss is complete with $\mathrm{R}=\mathrm{Ph}$, hence a weak exergonicity, and partial with $\mathrm{R}=2$-naphthyl, meaning an average exergonicity.

With $R=$ vinyl, the third step seems inaccessible, as reaching $T_{C D}$ would necessitate $38.0 \mathrm{kcal} / \mathrm{mol}$. Reaching $\mathbf{D}$ from $\mathbf{B}$ through $\mathbf{T S}_{\mathbf{B D}}$ is in fact even more difficult since a barrier of $39.5 \mathrm{kcal} / \mathrm{mol}$ would have to be overcome. Complex $\mathbf{C}$ could then give $\mathbf{G}$ and finally $\mathbf{H}$ through $\mathbf{T S}_{\mathbf{G H}}$, but this last step demands as much as $31.2 \mathrm{kcal} / \mathrm{mol}$ of free energy of activation. The last scenario in this case is the protodemetallation via $\mathbf{E}$ to give $\mathbf{F}$, which is indeed the product observed experimentally with $\mathrm{R}=$ vinyl. ${ }^{[17]}$

The $\mathrm{R}=2$-naphthyl showcases an interesting and subtle balance that rationalizes the different outcome compared to $R$ = vinyl. On one hand, the loss of aromaticity is only partial, so it does not hamper the formation of $\mathbf{C}$. On the other hand, the recovery of aromaticity facilitates the final Cope transposition that was impossible with $\mathrm{R}=$ vinyl.

The case of $\mathrm{R}=2$-furyl is also interesting and provides valuable confirmation of the existence of dearomatized intermediates $\mathbf{C}$ since this compound necessarily stems from the A-B-C-E-F pathway, similarly to the case of $\mathrm{R}=$ vinyl. The reaction from $\mathbf{1} \mathrm{i}$ leading to $\mathbf{8}$ also testifies that the 5 -exo-trig initial addition of the amine to the allene is thermodynamically favored over the 6-exo-dig addition, but is in most cases unproductive and reversible. This was the case in our previous studies with allyl groups, where the 5-exo-trig addition ( $\Delta G_{353}=1.6 \mathrm{kcal} / \mathrm{mol}, \mathbf{H}-19.6 \mathrm{kcal} / \mathrm{mol}$ ) was calculated to be favored over the 6-exo-dig addition $\left(\Delta G_{353}=7.3 \mathrm{kcal} / \mathrm{mol}, \mathbf{H}-22.2 \mathrm{kcal} / \mathrm{mol}\right.$, see also Figure 1). ${ }^{[17]}$ On the contrary, with $\mathrm{R}=$ indolyl, intermediate $\mathbf{H}$ is probably formed easily but evolves because of the electron-density of the indolyl moiety (see Scheme 5, eq. 3).

In conclusion, we have reported a new type of carboamination reaction of allenes with tertiary amines, leading to unstable enamine products that were converted to stable polycyclic scaffolds via a reductive treatment or an acidic hydrolysis protocol. This set of results is a proof of concept that allenes can undergo carboaminations of amines with the transfer of a benzylic group, with interesting mechanistic pathways ongoing and original elementary steps, such as the dearomatization/cope rearrangement sequence. These steps could be assessed by DFT calculations and experimentally verified by the reaction of a number of starting material that probed the mechanistic pathways.

\section{Acknowledgements}

Pierre Milcendeau thanks the CHARMMMAT Laboratory of Excellence (ANR-11-LABX0039) and the Université Paris-Saclay for financial support. This work was granted access to the HPC resources of CINES under the allocation 2020-A0070810977 made by GENCI.

\section{References}

[1] a) A. S. K. Hashmi, Angew. Chem. Int. Ed. 2010, 49, 5232; b) N. Bongers, N. Krause, Angew. Chem. Int. Ed. 2008, 47, 2178; c) A. Fürstner, Chem. Soc. Rev. 2009, 38, 3208; d) A. Arcadi, Chem. Rev. 2008, 108, 3266; e) M. Rudolph, A. S. K. Hashmi, Chem. Soc. Rev. 2012, 41, 2448; f) A. S. K. Hashmi, M. Rudolph, Chem. Soc. Rev. 2008, 37, 1766; g) V. K.-Y. Lo, A. O.-Y. Chan, C.-M. Che, Org. Biomol. Chem. 2015; h) M. Chiarucci, M. Bandini, Beilstein J. Org. Chem. 2013, 9, 2586; i) A. Fürstner, Acc. Chem. Res. 2014, 47, 925; j) E. Jiménez-Núñez, A. M. Echavarren, Chem. Rev. 2008, 108, 3326. 
[2] a) A. Pradal, P. Y. Toullec, V. Michelet, Synthesis 2011, 1501; b) H. Teller, S. Flügge, R. Goddard, A. Fürstner, Angew. Chem. Int. Ed. 2010, 49, 1949; c) S. Sengupta, X. Shi, ChemCatChem 2010, 2, 609; d) R. A. Widenhoefer, Chem. Eur. J. 2008, 14, 5382; e) W. Zi, D. F. Toste, Chem. Soc. Rev. 2016, 45, 4567.

[3] a) M. Rudolph, A. S. K. Hashmi, Chem. Commun. 2011, 47, 6536; b) M. H. Vilhelmsen, A. S. K. Hashmi, in PATAl'S Chemistry of Functional Groups, John Wiley \& Sons, Ltd, 2009; c) J. Britton, J. E. Camp, Chem. Today 2012, 30, 6; d) H. Huang, Y. Zhou, H. Liu, Beilstein J. Org. Chem. 2011, 7, 897; e) R. A. Widenhoefer, X. Han, Eur. J. Org. Chem. 2006, 2006, 4555.

[4] a) Y. Fukumoto, J. Synth. Org. Chem. Jpn. 2009, 67, 735; b) T. E. Mueller, K. C. Hultzsch, M. Yus, F. Foubelo, M. Tada, Chem. Rev. 2008, 108, 3795; c) I. Aillaud, J. Collin, J. Hannedouche, E. Schulz, Dalton Trans. 2007, 5105; d) R. Severin, S. Doye, Chem. Soc. Rev. 2007, 36, 1407; e) S. Matsunaga, J. Synth. Org. Chem. Jpn. 2006, 64, 778; f) R. A. Widenhoefer, X. Han, Eur. J. Org. Chem. 2006, 4555; g) Y. Yamamoto, U. Radhakrishnan, Chem. Soc. Rev. 1999, 28, 199.

[5] a) E. Mizushima, T. Hayashi, M. Tanaka, Org. Lett. 2003, 5, 3349; b) X. Zeng, M. Soleilhavoup, G. Bertrand, Org. Lett. 2009, 11, 3166; c) V. S. Shinde, M. V. Mane, K. Vanka, A. Mallick, N. T. Patil, Chem. Eur. J. 2015, 21, 975; d) A. W. Gregory, P. Jakubec, P. Turner, D. J. Dixon, Org. Lett. 2013, 15, 4330; e) S. Fustero, P. Bello, J. Miró, M. Sánchez-Roselló, M. A. Maestro, J. González, C. Del Pozo, Chem. Commun. 2013, 49, 1336; f) S. Kramer, J. L. H. Madsen, M. Rottlander, T. Skrydstrup, Org. Lett. 2010, 12, 2758; g) X. Zeng, G. D. Frey, S. Kousar, G. Bertrand, Chem. Eur. J. 2009, 15, 3056; h) Z.-Y. Han, H. Xiao, X.-H. Chen, L.-Z. Gong, J. Am. Chem. Soc. 2009, 131, 9182; i) A. Danda, K. Kumar, H. Waldmann, Chem. Commun. 2015, 51, 7536.

[6] a) R. Blieck, M. Taillefer, F. Monnier, Chem. Rev. 2020, 10.1021/acs.chemrev.0c00803; b) T. J. Brown, D. Weber, M. R. Gagne, R. A. Widenhoefer, J. Am. Chem. Soc. 2012, 134, 9134; c) Z. J. Wang, D. Benitez, E. Tkatchouk, W. A. Goddard, F. D. Toste, J. Am. Chem. Soc. 2010, 132, 13064; d) K. Aikawa, M. Kojima, K. Mikami, Adv. Synth. Catal. 2010, 352, 3131; e) R. LaLonde, Z. Wang, M. Mba, A. Lackner, F. Toste, Angew. Chem. Int. Ed. 2010, 49, 598; f) Z. Zhang, C. F. Bender, R. A. Widenhoefer, Org. Lett. 2007, 9, 2887; g) Z. Zhang, R. A. Widenhoefer, Angew. Chem. Int. Ed. 2007, 46, 283; h) G. L. Hamilton, E. J. Kang, M. Mba, F. D. Toste, Science 2007, 317, 496; i) R. L. LaLonde, B. D. Sherry, E. J. Kang, F. D. Toste, J. Am. Chem. Soc. 2007, 129, 2452.

[7] a) X.-Y. Liu, C.-H. Li, C.-M. Che, Org. Lett. 2006, 8, 2707; b) C. F. Bender, R. A. Widenhoefer, Chem. Commun. 2006, 4143; c) C. Michon, M.-A. Abadie, F. Medina, F. Agbossou-Niedercorn, Catalysis Today 2014, $235,2$.

[8] M. N. Hopkinson, A. D. Gee, V. Gouverneur, Chem. Eur. J. 2011, 17, 8248.

[9] a) A. Iglesias, K. Muñiz, Chem. Eur. J. 2009, 15, 10563; b) T. de Haro, C. Nevado, Angew. Chem. Int. Ed. 2011, 50, 906; c) G. Zhang, L. Cui, Y. Wang, L. Zhang, J. Am. Chem. Soc. 2010, 132, 1474; d) G. Zhang, Y. Luo, Y. Wang, L. Zhang, Angew. Chem. Int. Ed. 2011, 50, 4450; e) W. E. Brenzovich Jr., D. Benitez, A. D. Lackner, H. P. Shunatona, E. Tkatchouk, W. A. Goddard III, F. D. Toste, Angew. Chem. Int. Ed. 2010, 49, 5519; f) B. Sahoo, M. N. Hopkinson, F. Glorius, J. Am. Chem. Soc. 2013, 135, 5505.

[10] a) I. Nakamura, T. Sato, Y. Yamamoto, Angew. Chem. Int. Ed. 2006, 45, 4473; b) I. Nakamura, T. Sato, M. Terada, Y. Yamamoto, Org. Lett. 2008, 10, 2649; c) T. Sato, I. Nakamura, M. Terada, Eur. J. Org. Chem. 2009, 2009, 5509.

[11] I. Nakamura, T. Sato, M. Terada, Y. Yamamoto, Org. Lett. 2007, 9, 4081.

[12] Z.-C. Ding, H.-T. Tang, R.-H. Li, L.-C. Ju, Z.-P. Zhan, J. Org. Chem. 2015, 80, 9307.

[13] a) Y. Tokimizu, S. Oishi, N. Fujii, H. Ohno, Angew. Chem. Int. Ed. 2015, 54, 7862; b) M. Taguchi, Y. Tokimizu, S. Oishi, N. Fujii, H. Ohno, Org. Lett. 2015, 17, 6250.

[14] a) M. Uemura, I. D. G. Watson, M. Katsukawa, F. D. Toste, J. Am. Chem. Soc. 2009, 131, 3464; b) M. C. Blanco Jaimes, V. Weingand, F. Rominger, A. S. K. Hashmi, Chem. Eur. J. 2013, 19, 12504; c) M. Ackermann, J. Bucher, M. Rappold, K. Graf, F. Rominger, A. S. K. Hashmi, Chem. Asian J. 2013, 8, 1786; d) F. M. Istrate, F. Gagosz, Org. Lett. 2007, 9, 3181; e) F. M. Istrate, F. Gagosz, Beilstein J. Org. Chem. 2011, 7, 878; f) K. C. Majumdar, S. Hazra, B. Roy, Tetrahedron Lett. 2011, 52, 6697; g) F. Kolundžić, A. Murali, P. Pérez-Galán, J. O. Bauer, C. Strohmann, K. Kumar, H. Waldmann, Angew. Chem. Int. Ed. 2014, 53, 8122; h) V. Gobé, P. Retailleau, X. Guinchard, Chem. Eur. J. 2015, 21, 17587.

[15] a) P. Milcendeau, N. Sabat, A. Ferry, X. Guinchard, Org. Biomol. Chem. 2020, 18, 6006; b) V. Pirovano, Eur. J. Org. Chem. 2018, 2018, 1925.

[16] a) Z. Zhang, V. Smal, P. Retailleau, A. Voituriez, G. Frison, A. Marinetti, X. Guinchard, J. Am. Chem. Soc. 2020, 142, 3797; b) N. Sabat, F. Soualmia, P. Retailleau, A. Benjdia, O. Berteau, X. Guinchard, Org. Lett. 2020, 22, 4344; c) V. Magné, Y. Sanogo, C. S. Demmer, P. Retailleau, A. Marinetti, X. Guinchard, A. Voituriez, ACS Catal. 2020, 10, 8141; d) N. Glinsky-Olivier, S. Yang, P. Retailleau, V. Gandon, X. Guinchard, Org. Lett. 2019, 21, 9446; e) N. Glinsky-Olivier, P. Retailleau, X. Guinchard, Eur. J. Org. Chem. 2018, 2018, 5823; f) V. Magné, A. Marinetti, V. Gandon, A. Voituriez, X. Guinchard, Adv. Synth. Catal. 2017, 359, 4036; g) V. Magné, F. Blanchard, A. Marinetti, A. Voituriez, X. Guinchard, Adv. Synth. Catal. 2016, 358, 3355

[17] a) V. Gobé, M. Dousset, P. Retailleau, V. Gandon, X. Guinchard, J. Org. Chem. 2018, 83, 898; b) V. Gobé, M. Dousset, P. Retailleau, V. Gandon, X. Guinchard, Adv. Synth. Catal. 2016, 358, 3960. 
[18] A. Fürstner, P. W. Davies, Angew. Chem. Int. Ed. 2007, 46, 3410.

[19] This reaction is however successful with ynamides in place of alkynes. See ref. 14b.

[20] a) A. Calcaterra, L. Mangiardi, G. Delle Monache, D. Quaglio, S. Balducci, S. Berardozzi, A. lazzetti, R. Franzini,

B. Botta, F. Ghirga, Molecules 2020, 25; b) C. Zheng, Z.-L. Xia, S.-L. You, Chem 2018, 4, 1952; c) N. Glinsky-Olivier,

X. Guinchard, Synthesis 2017, 49, 2605; d) C. Ingallina, I. D'Acquarica, G. Delle Monache, F. Ghirga, D. Quaglio,

P. Ghirga, S. Berardozzi, V. Markovic, B. Botta, Curr. Pharm. Des. 2016, 22, 1808; e) J. Stockigt, A. P. Antonchick,

F. R. Wu, H. Waldmann, Angew. Chem. Int. Ed. 2011, 50, 8538.

[21] C. Nieto-Oberhuber, S. López, A. M. Echavarren, J. Am. Chem. Soc. 2005, 127, 6178.

[22] N. Mézailles, L. Ricard, F. Gagosz, Org. Lett. 2005, 7, 4133.

[23] Without protection, the product spontaneously cyclises back to the enamine $\mathbf{2 a}$.

[24] Z. Zhang, S. Du Lee, A. S. Fisher, R. A. Widenhoefer, Tetrahedron 2009, 65, 1794.

[25] a) H. V. Adcock, T. Langer, P. W. Davies, Chem. Eur. J. 2014, 20, 7262; b) W. Zi, F. D. Toste, J. Am. Chem. Soc.

2013, 135, 12600; c) D. M. Schultz, N. R. Babij, J. P. Wolfe, Adv. Synth. Catal. 2012, 354, 3451.

[26] Z. J. Garlets, D. R. White, J. P. Wolfe, Asian J. Org. Chem. 2017, 6, 636.

[27] a) I. Nakamura, Y. Mizushima, Y. Yamamoto, J. Am. Chem. Soc. 2005, 127, 15022; b) I. Nakamura, C. S. Chan, T. Araki, M. Terada, Y. Yamamoto, Adv. Synth. Catal. 2009, 351, 1089.

[28] a) V. Gobé, X. Guinchard, Chem. Eur. J. 2015, 21, 8511 ; b) V. Gobé, X. Guinchard, Org. Lett. 2014, 16, 1924.

[29] In our previous papers using allyl migrating groups, we showed that 5-exo cyclizations is the kinetically favored mode of addition of the amine to the allene. However, in most cases, this is an unproductive intermediate. See ref 17.

[30] a) A. Noble, J. C. Anderson, Chem. Rev. 2013, 113, 2887; b) J. Xie, H. Li, J. Zhou, Y. Cheng, C. Zhu, Angew. Chem. Int. Ed. 2012, 51, 1252; c) C. Qian, F. Gao, R. Chen, Tetrahedron Lett. 2001, 42, 4673.

[31] Of note, with $\mathrm{R}=2$-naphthyl, we show only the formation of the $\mathrm{C}-\mathrm{C}$ bond in $\mathrm{C}$ involving the ortho carbon. It was also studied using the meta carbon, but it was found much less favorable ( $\mathrm{TS}_{\mathrm{BC}}$ at $20.8 \mathrm{kcal} / \mathrm{mol}$ instead or $12.8 \mathrm{kcal} / \mathrm{mol}$; $\mathbf{C}$ at $2.4 \mathrm{kcal} / \mathrm{mol}$ instead of $-17.8 \mathrm{kcal} / \mathrm{mol})$. This regioselectivity is consistent of that of the $\mathrm{SE}_{A r}$ and can be easily explained by the stability of the resonance structures. 
